\title{
Association of rs1800471 polymorphism of TGFB1 gene with chronic kidney disease occurrence and progression and hypertension appearance
}

\author{
Katarzyna Nabrdalik, Janusz Gumprecht, Piotr Adamczyk, Sylwia Górczyńska-Kosiorz, \\ Joanna Żywiec, Władysław Grzeszczak
}

Department of Internal Diseases, Diabetology and Nephrology, Medical University of Silesia, Zabrze, Poland

Submitted: 20 June 2012

Accepted: 16 November 2012

Arch Med Sci 2013; 9, 2: 230-237

DOI: 10.5114/aoms.2013.34418

Copyright @ 2013 Termedia \& Banach

\section{Abstract}

Introduction: Transforming growth factor $\beta 1$ (TGF- $\beta 1$ ) is a cytokine involved in the process of pathological tissue sclerosis, which is part of the pathophysiological mechanism of end stage renal disease development. The aim of the study was to evaluate the association of the single nucleotide polymorphism rs 1800471 of the TGFB1 gene with chronic kidney disease (CKD) occurrence and progression as well as hypertension appearance.

Material and methods: It was a case-control study where 109 patients with CKD and 111 very old people were enrolled. The association of the studied polymorphism with mentioned diseases was assessed in the whole study group as well as in the subgroups stratified according to the underlying etiology of CKD: nephropathy in type 1 diabetes $(n=13)$, chronic glomerulonephritis $(n=50)$ and chronic interstitial nephritis $(n=46)$.

Results: No association of CKD progression with rs1800471 polymorphism was observed. The $C$ allele was identified as the one associated with higher risk of the disease occurrence in the dominant model of inheritance $(p=0.035)$. The $C$ allele in women, opposite to male gender, was associated with higher risk of CKD development $(p=0.038)$. GG genotype was associated with elevated risk of hypertension appearance $(p=0,0021)$.

Conclusions: Due to the lack of accordance with previously performed studies it is still impossible to state an unequivocal conclusion regarding the association between rs 1800471 polymorphism of the TGFB1 gene and risk of CKD occurrence and progression as well as hypertension appearance. That is why it is necessary to perform further studies in this field

Key words: case-control study, very old people, genetic risk factors, kidney diseases.

\section{Introduction}

Chronic kidney disease (CKD) prevalence is high and the disease is associated with significant morbidity and is a direct risk factor for development of cardiovascular complications. The environmental risk factors of CKD occurrence and progression that have been recognized to date are not sufficient for identification of groups of people at higher risk of disease development as well as to develop new and efficient treatment methods. In view of the foregoing there are a lot of expectations placed on the genetic factors, along with environmental ones, related to CKD occurrence and progression [1, 2]. Genetic factors frequently manifest only in the pres-

\section{Corresponding author:}

Katarzyna Nabrdalik MD, PhD

Department of Internal

Diseases, Diabetology

and Nephrology

Medical University of Silesia

13-15 3 Maja St

41-800 Zabrze, Poland

Phone: +48 323704415

E-mail:

knabrdalik@yahoo.com 
ence of special situations such as presence of other diseases, for example diabetes mellitus or hypertension. However, not everyone who suffers from these conditions develops renal disease or progresses to ESRD. That is why it is likely that genetic factors determine the time of onset and the rate of progression of CKD.

Due to the hypothesis that common genetic variants predispose to common diseases there is growing interest in single nucleotide polymorphisms (SNPS) [3].

Regardless of the primary etiology of CKD, kidney tissue progressive fibrosis and subsequent sclerosis is a common pathological phenomenon characteristic for ESRD [4]. Fundamentally linked to the pathogenesis of renal interstitial fibrosis is a process called epithelial-to-mesenchymal transition (EMT) of mature tubular epithelial cells in adult kidney leading to accumulation and deposition of extracellular matrix (ECM) and tissue fibrosis [5]. In the process of CKD progression to the terminal stage, the renin-angiotensin-aldosterone system is involved and many researchers focus lately on the cytokine mediating angiotensin action, namely TGF- $\beta 1$. This is a multipotent cytokine involved in the process of EMT and production of ECM $[6,7]$. Enhanced expression of the TGFB1 gene is one of the most permanent molecular changes causing pathological tissue fibrosis. There is an opinion that overproduction of TGF- $\beta$, partly stimulated by angiotensin II, beside favouring progression of CKD is also linked with hypertension occurrence $[4,8]$.

There have been several polymorphisms of the TGFB1 gene identified to date and three of them influence expression of the TGFB1 gene and cytokine production. The most frequently studied associations of the TGFB1 gene with CKD occurrence and/or progression have been polymorphisms rs1982073 (+869T/C) and rs1800471 (+915G/C) [9]. Carriers of the $C$ allele of rs1982073 polymorphism as well as carriers of the $G$ allele of rs1800471 polymorphism are characterised by a higher amount of plasma TGF- $\beta 1$ [10].

In the study performed among Chinese with CKD of different origin (non-diabetic) there was a predisposition to CKD occurrence found only in males who were carriers of TC genotype of rs1982073 polymorphism [11]. In the study performed by Khalil et al. among Caucasians with CKD of different origin there was an association of rapid progression of CKD with GG genotype of rs1800471 polymorphism [12]. Predisposition to diabetic nephropathy occurrence was found by Patel et al. among Caucasians with type 1 diabetes mellitus carrying TT genotype of rs1982073 polymorphism [13]. These outcomes are opposite to the ones obtained by $\mathrm{Ng}$ et al. and McKnight et al., who did not find increased susceptibility to diabetic nephropathy occurrence associated with either rs1982073 or rs1800471 polymorphism of the TGFB1 gene [14, 15]. Buraczynska et al. and Babel et al. found that TT genotype of rs1982073 polymorphism predisposes to CKD occurrence in type 2 diabetic patients but could not identify such an association regarding rs1800471 polymorphism $[16,17]$. Predisposition to hypertension occurrence has been recognized in Caucasians without coexisting kidney disease, carriers of GG genotype of rs1800471 polymorphism in the study performed by Cambien et al. and confirmed by Li et al. in Caucasians and Blacks [8, 9]. In the study performed among patients with chronic glomerulonephritis there was no association found between rs1982073 and rs1800471 polymorphisms and progression of CKD [18].

Performed studies describing the association of different polymorphisms of the TGFB1 gene with CKD and cardiovascular disease occurrence and progression present contradictory outcomes. It appears that only rs1800471 polymorphism predisposes to CKD as well as hypertension occurrence in the group of people without CKD. That is why it seems important to continue studies of this polymorphism and check whether there is an association between rs1800471 polymorphism and hypertension occurrence in people with CKD and progression of CKD of different origin.

The aim of the study was to evaluate the association of rs1800471 polymorphism of the TGFB1 gene (candidate gene) with occurrence and progression of CKD as well as with hypertension appearance. The gene of this cytokine was chosen due to the involvement of TGF- $\beta 1$ in the process of pathological tissue sclerosis that is part of the common pathophysiological mechanism of ESRD development as well as ambiguous outcomes of previously performed studies.

\section{Material and methods}

\section{Subjects}

It was a case-control association study of the rs1800471 polymorphism of the TGFB1 gene where the genotype and allele distributions were compared between 109 genetically unrelated Caucasian patients with CKD (estimated glomerular filtration rate (eGFR) $<60 \mathrm{ml} / \mathrm{min} / 1.73 \mathrm{~m}^{2}$ ) at mean $25.4 \pm 12.9$ years of age, 46 women (42\%) at mean $27.3 \pm 12.2$ years of age and 63 men (58\%) at mean $24.0 \pm 13.3$ years of age (study group) and 111 genetically unrelated Caucasian very old people without any signs of CKD or hypertension, at mean $92.7 \pm 3.1$ years of age, 70 women $(71 \%)$ at mean $92.1 \pm 2.6$ years of age and 32 men (29\%) at mean $92.9 \pm 3.2$ years of age, who due to their age are probably not affected by the genetic risk factors causing development of dynamically progressing 
chronic diseases leading to premature death (control group).

The main inclusion criterion for patients from the study group was the existence of CKD in at least stage 3 of the disease (eGFR $<60 \mathrm{ml} / \mathrm{min} /$ $1.73 \mathrm{~m}^{2}$ ) and the main inclusion criteria for people from the control group were age of at least 90 years and no clinical signs of CKD and hypertension.

The association of different allelic forms of the studied gene was assessed in the whole study group as well as in the subgroups stratified according to the underlying aetiology of CKD: 13 people with chronic diabetic kidney disease in the course of type 1 diabetes, 50 people with chronic glomerulonephritis and 46 people with chronic interstitial nephritis.

Evaluation was carried out on patients with CKD being treated in the nephrology outpatient clinic as well as on patients on maintenance haemodialysis therapy in the Nephrology Clinic in Zabrze as well as in patients without any signs of CKD and hypertension being treated in the Geriatric Department of the hospital in Sosnowiec. The study was carried out in accordance with the Declaration of Helsinki, and the protocol was approved by the University Ethics Committee.

\section{Diagnosis of underlying aetiology of chronic kidney disease}

Diagnosis of diabetic nephropathy was made after examination of urinary albumin (obtaining in two out of three measurements an outcome of 30-299 mg albumin in 24-hour urine collection or $\geq 300 \mathrm{mg}$ of protein in 24-hour urine collection) and analysis of clinical history (lack of other clinical and laboratory signs of kidney or urinary tract disease). Urinary albumin was measured using a commercially available kit. The urine collection procedure was performed from 8:00 p.m. to 8:00 a.m. during 3 consecutive days.

Diagnosis of chronic glomerulonephritis was made on the basis of clinical history and existence of persistent proteinuria and/or haematuria or cylindruria as well as coexisting decreased of eGFR value. Additionally, in a group of 13 patients diagnosis was confirmed by kidney biopsy.

Diagnosis of chronic interstitial nephritis was made on the basis of clinical history confirming existence of recurrent urinary tract infections, pathological image in ultrasound examination and/or urography examination and pathological urine sediment.

\section{Genotyping of rs 1800471 polymorphism}

Genomic DNA was extracted from frozen whole blood samples containing EDTA as an anticoagulant using the MasterPure TM DNA purification kit (Epicentre Technologies) and resuspended in TE. Genotyping was performed by the method described pre- viously by Wood et al. [19]. Primers (Tip MolBiol) used for amplification were as follows: forward 5' TTC CCT CGA GGC CCT CCT A 3'; and reverse: 5' GCC GCA GCT TGG ACA GGA TC 3'. PCR amplification was performed in a total volume of $25 \mu \mathrm{l}$ which contained $100 \mathrm{ng}$ of genomic DNA. The reaction mixture contained: $10 \mathrm{mmol} / / \mathrm{l}$ Tris $\mathrm{HCl}, \mathrm{pH} 8.8,50 \mathrm{mmol} / \mathrm{l} \mathrm{KCl}$, $1.5 \mathrm{mmol} / \mathrm{I} \mathrm{MgCl}_{2}, 0.1 \%$ Triton X-100, $2.5 \mathrm{mmol} / \mathrm{l}$ of each deoxynucleotide triphosphate, $10 \mathrm{pmol}$ of each primer, $1.5 \mathrm{mmol} / \mathrm{l}-1$ magnesium chloride and $0.6 \mathrm{U}$ of thermostable Taq DNA polymerase (DyNAzyme TM II, Finnzymes). PCR amplification consisted of an initial denaturation at $94^{\circ} \mathrm{C}$ for 5 min, followed by 35 cycles of denaturation at $94^{\circ} \mathrm{C}$ for $1 \mathrm{~min}$, annealing at $58^{\circ} \mathrm{C}$ for $1 \mathrm{~min}$, and extension at $72^{\circ} \mathrm{C}$ for $1 \mathrm{~min}$, and a final extension at $72^{\circ} \mathrm{C}$ for 10 min. PCR products were digested with $\mathrm{Bgl}$ I enzyme (Fermentas) for the detection of polymorphism $+915 G / C$ of the TGFB1 gene. All samples were analysed on 4\% agarose gel electrophoresis and visualized by ethidium bromide staining in UV light (Vilber Loumat transilluminator UV). Genotyping was performed in a blinded fashion.

\section{Other determinants and data processing}

Anthropometric measurements (height and weight) were measured by standard methods. Serum creatinine was measured by Jaffe's method (Cobas Integra 800, Roche Diagnostics).

All patients from the study group had BMI calculated as weight/height ${ }^{2}\left(\mathrm{~kg} / \mathrm{m}^{2}\right)$ and the glomerular filtration rate (GFR) per $1.73 \mathrm{~m}^{2}$ estimated according to MDRD [20]: $186 \times($ serum creatinine $(\mathrm{mg} / \mathrm{dl}))-1.154$ $\times$ (age (years) $)-0.203 \times(0.742$ if female $)$ and according to the Schwartz equation if the patient was under the age of 18 [21]: coefficient $\times$ (body length $(\mathrm{cm})$ )/ (serum creatinine $(\mathrm{mg} / \mathrm{dl})$ ), where the coefficient was 0.45 if $<2$ years of age, 0.55 if $>2$ years of age and 0.7 if $\geq 13$ years of age. Stages of CKD were defined according to standards [22]. It was presupposed that in order to evaluate progression of CKD patient follow-up cannot be shorter than 6 months.

Progression of CKD was assessed as mean reduction of eGFR per year. Reduction of eGFR $\geq 4 \mathrm{ml}$ $\mathrm{min} / 1.73 \mathrm{~m}^{2} /$ year was assumed as severe progression of CKD and reduction of eGFR $\leq 4 \mathrm{ml} / \mathrm{min} /$ $1.73 \mathrm{~m}^{2} /$ year was assumed as benign progression of CKD because the value $4 \mathrm{ml} / \mathrm{min} / 1.73 \mathrm{~m}^{2}$ was the closest to the median annual eGFR reduction calculated for the whole group and subgroup of patients with CKD.

\section{Statistical analysis}

All statistical calculations were performed using Microsoft Office Excel 2003 and Statistica 8.0, StatSoft Inc (USA). 
The Shapiro-Wilk test for normality was used. Descriptive statistics for continuous parameters of normal distribution were arithmetic means \pm SD (standard deviation) or geometric means (interquartile range) for continuous data that did not have normal distribution. Categorical variables were absolute value and percentage.

Accordance with Hardy-Weinberg was tested with Pearson's $\chi^{2}$ test with Yates correction. Differences among categorical variables were assessed by Pearson's $\chi^{2}$ test or Fisher's exact test. Differences among continuous variables were tested by ANOVA (analysis of variance) for single classification with post hoc analysis of least significant differences. To assess the equality of variances in different samples the Levene test was used.

Genetic relationships with study variables were analysed by an additive model with $2 \times 3$ contingency tables. For a rare allele a dominant model was applied (GG vs. GC + CC) using Fisher's exact test and $2 \times 2$ contingency tables. This model is used for identification of the influence of a rare allele on expression of a phenotypic trait.

The odds ratio with $95 \%$ confidence interval was calculated and a logistic regression model was used to evaluate the independent influence of the analysed parameters, in the study group of people with CKD in relation to people from the control group, on the progression of CKD (hypertension, CKD aetiology, genotype, sex, age, BMI, eGFR at the beginning of observation) as well as hypertension occurrence (CKD aetiology, genotype, sex, age, BMI, eGFR at the beginning of observation, stage 5 of CKD, CKD progression rate).

The two-tailed statistical significance was set at $p<0.05$.

\section{Results}

Genotypic proportions of rs1800471 polymorphism of the TGFB1 gene in study and control groups were in Hardy-Weinberg equilibrium.

The genotype and allele distribution in the study and control group was respectively: GG genotype $77 \%$, GC genotype $-19 \%$; CC genotype $-4 \%$, $\mathrm{G}$ allele $-87 \%$ and $\mathrm{C}$ allele $-13 \%$ vs. GG genotype - $86 \%$, GC genotype - 14\%, CC genotype - 0\%, $\mathrm{G}$ allele $-93 \%$ and $\mathrm{C}$ allele $-7 \%$ (Table I).
A significant difference was found in genotype frequencies between patients with diabetic nephropathy and the control group $(p=0.013)$. Allele $C$ frequency was significantly higher in the whole study group of people with CKD compared to the control group, which translated into two times higher risk of CKD occurrence in this group of people $(\mathrm{OR}=2.0 ; 95 \% \mathrm{Cl}: 1.0-3.8 ; p=0.035)$ (Table II).

Significant differences were also found in genotype frequencies in the dominant as well as in the additive model among women from the whole study group ( $p=0.038$ ) as well as in the subgroup of chronic intestinal nephritis $(p=0.042)$ compared to women from the control group, which regarding the dominant genetic model translated into almost 3 times elevated risk of CKD occurrence in the whole study group and more than 5 times in the subgroup of women with chronic intestinal disease who were carriers of GG or GC genotype $(\mathrm{OR}=2.7$; 95\% Cl: 1.1-6.8; $p=0.03$ and $\mathrm{OR}=5 ; 95 \% \mathrm{Cl}$ : 1.6-15.5; $p=0.003$, respectively). When analysing allele $C$ occurrence in women the risk of CKD development was elevated almost 3 times in the whole study group and more than 4.5 times in women from the subgroup of chronic interstitial kidney disease $(\mathrm{OR}=2.9 ; 95 \% \mathrm{Cl}: 1.2-6.7 ; p=0.011$ and $\mathrm{OR}=4.6$; $95 \% \mathrm{Cl}: 1.7-12.3 ; p=0.001$, respectively) compared to women from the control group. There was no risk elevation associated with male gender and simultaneous $C$ allele or $G$ allele presence (data not shown). There was no differences in genotype or allele frequencies found in the dominant or the additive model of genotype in males.

No significant differences were found in genotype or allele frequencies distribution between groups with severe and benign progression of CKD either in the whole study group of people with CKD or in subgroups of people identified by underlying aetiology (Table III). Logistic regression analysis identified underlying aetiology of CKD, namely diabetic nephropathy and chronic glomerulonephritis, as risk factors independently connected with higher risk of severe progression of CKD (Table IV).

Significant differences were found in the genotype frequencies in the additive model in the whole

Table I. Distribution of genotypes and alleles among study and control group

\begin{tabular}{|lccccc|}
\hline $\begin{array}{l}\text { Genotypes } \\
\text { and alleles }\end{array}$ & $\begin{array}{c}\text { Study group } \\
(n=109)\end{array}$ & $\begin{array}{c}\text { Diabetic nephropathy } \\
(n=13)\end{array}$ & $\begin{array}{c}\text { Chronic glomerulonephritis } \\
(n=50)\end{array}$ & $\begin{array}{c}\text { Chronic interstitial } \\
\text { nephritis }(n=46)\end{array}$ & $\begin{array}{c}\text { Control group } \\
(n=111)\end{array}$ \\
\hline G/G genotype & $84(77 \%)$ & $10(77 \%)$ & $39(78 \%)$ & $25(76 \%)$ & $95(86 \%)$ \\
\hline G/C genotype & $21(19 \%)$ & $2(15 \%)$ & $9(18 \%)$ & $10(22 \%)$ & $16(14 \%)$ \\
\hline C/C genotype & $4(4 \%)$ & $1(8 \%)$ & $2(4 \%)$ & $1(2 \%)$ & $0(0 \%)$ \\
\hline G allele & $189(87 \%)$ & $22(85 \%)$ & $87(87 \%)$ & $80(87 \%)$ & $206(93 \%)$ \\
\hline C allele & $29(13 \%)$ & $4(15 \%)$ & $13(13 \%)$ & $12(13 \%)$ & $16(7 \%)$ \\
\hline
\end{tabular}


Table II. Genotype and allele frequencies of rs1800471 polymorphism of TGFB1 gene in study and control group

\begin{tabular}{|c|c|c|c|c|c|}
\hline & $\begin{array}{l}\text { Study group } \\
(n=109)\end{array}$ & $\begin{array}{l}\text { Diabetic nephropathy } \\
\qquad(n=13)\end{array}$ & $\begin{array}{l}\text { Chronic glomerulonephritis } \\
\qquad(n=50)\end{array}$ & $\begin{array}{c}\text { Chronic interstitial } \\
\text { nephritis }(n=46)\end{array}$ & $\begin{array}{c}\text { Control group } \\
(n=111)\end{array}$ \\
\hline \multicolumn{6}{|l|}{ Additive model } \\
\hline G/G genotype & $84(77 \%)$ & $10(77 \%)$ & $39(78 \%)$ & 35 (76\%) & 95 (86\%) \\
\hline G/C genotype & $21(19 \%)$ & $2(15 \%)$ & $9(18 \%)$ & $10(22 \%)$ & $16(14 \%)$ \\
\hline $\mathrm{C} / \mathrm{C}$ genotype & $4(4 \%)$ & $1(8 \%)$ & $2(4 \%)$ & $1(2 \%)$ & $0(0 \%)$ \\
\hline$\chi^{2}$ & 5.53 & 8.65 & 4.96 & 3.82 & \\
\hline Value of $p$ & 0.069 & 0.013 & 0.083 & 0.148 & \\
\hline \multicolumn{6}{|l|}{ Allele } \\
\hline G & $189(87 \%)$ & $22(85 \%)$ & 87 (87\%) & $80(87 \%)$ & $206(93 \%)$ \\
\hline C & 29 (13\%) & $4(15 \%)$ & $13(13 \%)$ & $12(13 \%)$ & $16(7 \%)$ \\
\hline$\overline{\chi^{2}}$ & 4.45 & 2.1 & 2.82 & 2.73 & \\
\hline$\overline{O R}$ & 2.0 & 2.3 & 1.9 & 1.9 & \\
\hline $95 \% \mathrm{Cl}$ & $1.0-3.8$ & $0.7-7.6$ & $0.9-4.2$ & $0.9-4.3$ & \\
\hline Value of $p$ & 0.035 & 0.147 & 0.093 & 0.099 & \\
\hline
\end{tabular}

Table III. Genotype and allele frequencies of rs1800471 polymorphism of TGFB1 gene in groups of patients with benign and severe progression rate of CKD

\begin{tabular}{|lcccc|}
\hline & Allelic influence & Severe progression rate, $n^{\mathrm{a}}$ & Benign progression, $n^{\mathrm{b}}$ & Value of $p^{*}$ \\
\hline Study group $(n=109)$ & $\begin{array}{l}\text { Dominant model; } \\
\text { G/G vs. G/C + C/C }\end{array}$ & $38 / 14$ & $35 / 8$ & 0.3390 \\
\cline { 2 - 5 } & $\begin{array}{l}\text { Additive model: } \\
\text { G/G vs. G/C vs. C/C }\end{array}$ & $38 / 11 / 3$ & $35 / 7 / 1$ & 0.5571 \\
\cline { 2 - 5 } & G allele/C allele & $87 / 17$ & $77 / 9$ & 0.2400 \\
\hline $\begin{array}{l}\text { Diabetic nephropathy } \\
(n=13)\end{array}$ & $\begin{array}{l}\text { Dominant model: } \\
\text { G/G vs. G/C + C/C }\end{array}$ & $8 / 3$ & $1 / 0$ & 0.546 \\
\hline $\begin{array}{l}\text { Chronic glomerulonephritis } \\
(n=50)\end{array}$ & $\begin{array}{l}\text { Dominant model } \\
\text { G/G vs. G/C + C/C }\end{array}$ & $23 / 7$ & $10 / 3$ & 0.9850 \\
\hline $\begin{array}{l}\text { Chronic interstitial nephritis } \\
(n=46)\end{array}$ & $\begin{array}{l}\text { Dominant model } \\
\text { G/G vs. G/C + C/C }\end{array}$ & $7 / 4$ & $24 / 5$ & 0.1960 \\
\hline
\end{tabular}

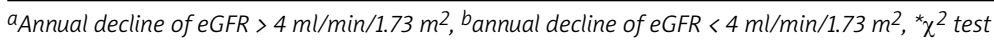

Table IV. Parameters associated independently with CKD occurrence

\begin{tabular}{|lcc|}
\hline Parameter & $\begin{array}{c}\text { Diabetic } \\
\text { nephropathy }\end{array}$ & $\begin{array}{c}\text { Chronic } \\
\text { glomerulonephritis }\end{array}$ \\
\hline$\chi^{2}$ Wald & 9.32 & 13.83 \\
\hline OR & 29 & 6.1 \\
\hline $95 \% \mathrm{Cl}$ & $3.2-259.3$ & $2.3-16.0$ \\
\hline Value of $p$ & $0.0023^{\mathrm{a}}$ & $0.0002^{\mathrm{a}}$ \\
\hline
\end{tabular}

OR - odds ratio, $95 \% \mathrm{Cl}$ - confidence interval, a logistic regression analysis

study group of people with CKD and hypertension, in the subgroup of people with diabetic nephropathy and hypertension as well as chronic glomerulonephritis and hypertension $\left(\chi^{2}=6.4, p=0.04\right.$ and $\chi^{2}=11.7, p=0.003$ and $\chi^{2}=5.84, p=0.05$, respectively). Additionally, genotype frequencies in the dominant model revealed more than 3 times ele- vated risk of hypertension occurrence in people with CKD (OR = 3.25; 95\% Cl: 1.29-8.21; $p=0.011)$. Etiology of CKD, namely diabetic nephropathy and chronic glomerulonephritis, female gender, and GG genotype were found to be independently associated with hypertension occurrence in the group of CKD people (Table V).

\section{Discussion}

On the basis of the performed analyses, the rs1800471 polymorphism of the TGFB1 gene has been proven to be associated with the occurrence of CKD. The mutant $C$ allele was identified as the one associated with higher risk of disease occurrence.

The mentioned risk was elevated 2-fold in the presence of the $C$ allele in the whole study group of people with CKD, independently of the underlying etiology of kidney disease. This observation is 
Table V. Parameters associated independently with hypertension occurrence

\begin{tabular}{|lcccc|}
\hline Parameter & Diabetic nephropathy & Chronic glomerulonephritis & Female gender & G/G genotype \\
\hline$\chi^{2}$ Wald & 5.4 & 14.04 & 7.73 & 9.45 \\
\hline OR & 8.5 & 8 & 4.9 & 5.9 \\
\hline $95 \% \mathrm{Cl}$ & $1.4-53.2$ & $2.0-24.2$ & $1.6-15.1$ & $1.9-18.4$ \\
\hline Value of $p$ & $0.0208^{\mathrm{a}}$ & $0.0002^{\mathrm{a}}$ & $0.0054^{\mathrm{a}}$ & $0.0021^{\mathrm{a}}$ \\
\hline
\end{tabular}

$O R$ - odds ratio, $95 \% \mathrm{Cl}$ - confidence interval, a logistic regression analysis

in accordance with the study performed by Mittal et al., who found an association with low-producing genotypes and of rs1800471 and rs1982073 polymorphisms with higher risk of CKD occurrence. These authors, in contrast to others, pointed out the potentially protective influence of higher TGFB1 gene expression and TGF- $\beta 1$ production because this cytokine plays a role not only in sclerosis but also in immunology system regulation, which is why it may influence the anti-inflammatory and immunoregulatory function [23]. Buraczynska et al. and Coll et al. also found an association of rs1800471 polymorphism of the TGFB1 gene with CKD occurrence but the outcome, in contrast to our study as well as the study performed by Mittal et al., was related to high producing genotypes of the mentioned polymorphism $[16,24]$. Outcomes of the above studies are in contrast with the ones performed by $\mathrm{Ng}$ et al., McKnight et al. and Babel et al. who found no association between rs1800471 polymorphism of the TGFB1 gene and CKD occurrence $[14,15,17]$. In a recent study, Dell'omo et al. did not find an association between the studied polymorphism of the TGFB1 gene and microalbuminuria among Caucasian hypertensive men [25]. In our study, allele $C$ was associated with increased risk of CKD occurrence in the group of women with CKD, regardless of underlying kidney disease etiology, and in the subgroup of women with chronic interstitial nephritis of 3 and more than 4.5 times, respectively. Previously no such association has been described in the literature. The only study to have found an association of polymorphism of the TGFB1 gene, namely rs1982073, and gender was the one performed by Kim et al., which revealed an association between carriers of TT genotype and higher risk of stroke identified among women. These authors tried to explain this phenomenon by the fact that in complex traits, effects of autosomal genes that are specific to gender can be explained by epistasis with sex-linked genes or by interplay with other factors correlated with gender [26]. TT genotype and the $T$ allele are associated with lower production of TGF- $\beta 1$ and a lower amount of this cytokine may be linked to reduction in estrogen receptor expression and limit the protective influence of estrogens on stroke occurrence $[27,28]$. Similarly, in our study increased risk of CKD among women, carriers of allele C, may be linked for example to gender-related hormones because it is known from the literature that oestrogen hormones may interact with the TGF- $\beta$ signalling pathways [29]. Maybe higher risk of CKD occurrence among women is linked to reduction of the positive influence of estrogens. The relation of sex dimorphism to CKD is still not well known. Even though male gender is thought to be associated with severe progression of CKD, it is still not known whether it is male or female gender that is at higher risk of CKD occurrence and progression and what is the potential mechanism of the phenomenon [30-32].

There was no association with rs1800471 polymorphism and CKD progression severity observed either in the dominant or the additive model of genotype frequencies, which is in contrast with the study performed by Khali et al., where GG genotype was associated with faster progression of CKD [12]. On the other hand, Coll et al., as well as Summers et al., did not find such an association [18, 24].

In our study a predisposition to faster decline of renal function was observed in the presence of nongenetic factors, namely hypertension, and underlying aetiology of CKD (diabetic nephropathy and chronic glomerulonephritis). Only the underlying aetiologies of CKD were independently associated with faster CKD progression rate. Diabetic nephropathy increased the risk 29 times and chronic glomerulonephritis 6 times. This observation is in accordance with other studies proving that CKD aetiology is one of the well-known factors determining the natural history of CKD. It is also underlined that despite the same aetiology of CKD the progression rate may be totally different, which shows the complexity of the process and the need for further studies looking for genetic factors responsible for the observed differences [33].

Regarding the risk of hypertension occurrence in people with CKD, we proved that carriers of GG genotype compared to carriers of the $C$ allele (GC and CC genotypes) had the risk elevated more than 3 times in the whole group of people with CKD as well as in the subgroup of patients with diabetic nephropathy and chronic glomerulonephritis. This outcome was also confirmed in logistic regression analysis where carrying the GG genotype was independently associated with almost 6 times elevat- 
ed risk of hypertension occurrence in the study group regardless of the underlying etiology. Our outcomes are in accordance with previous studies. In the ECTIM study a significant association of rs1800471 polymorphism of the TGFB1 gene and hypertension occurrence was identified [9]. Similarly, Li et al. reported higher risk of hypertension occurrence among carriers of the $G$ allele of the mentioned polymorphism [8]. The $\mathrm{G}$ allele is known to be a part of highly productive genotypes predisposing to production of larger amounts of cytokine, which is thought to predispose to hypertension [27, 34].

Surprisingly, while GG genotype was shown to be an independent risk factor of hypertension occurrence, it was also the most often represented genotype in the control group of very old people from control group. This phenomenon was previously described in the literature, where Carrieri et al. found GG genotype to be the most often present in the study group of very old people. The authors tried to explain this finding by showing that along with age there is an increase of diseases of immune etiology and the existence of a high cytokine producing genotype may have protective properties in this context since one of the features of TGF- $\beta 1$ is strong immunosuppressive activity [35].

We found an independent influence of female gender on hypertension occurrence, increasing the risk 5 times, as well as underlying aetiology of CKD (diabetic nephropathy and chronic glomerulonephritis increased this risk 8.5 and 8 times, respectively).

From literature information it is known that it is male gender that is more often predisposed to hypertension occurrence, which is why this finding requires further studies investigating hypertension occurrence among women compared with men. The obtained outcomes may also result from limitations of our study. First, we did not collect data regarding contraception treatment or hormonal substitution therapy or concomitant diseases that could predispose to hypertension occurrence among women.

We found, similar to other authors, late referral to a nephrologist in the studied patients with CKD; 14 out of 109 of them started renal replacement therapy 6 months after the first visit to the nephrology outpatient clinic (data not shown) [36]. This problem is addressed in the annually celebrated World Kidney Day, an event sponsored by the International Society of Nephrology and the International Federation of Kidney Foundations, raising awareness of the need for early detection and prevention of kidney disease in order to improve long-term health outcomes [37]. Even though there is development of molecular methods of detection of multifactorial diseases, for example genome wide association studies (GWAS) which enable simultaneous identification of thousands of single nucleotide polymorphisms (SNP) at one time, it is still important to perform case control studies where up to several SNPs may be studied. In GWAS there can be only polymorphic variants that often occur in the population identified according to the common diseasecommon genetic variant hypothesis. A limitation of such study is the lack of possibility to identify SNPS of rare occurrence (less than 5\%), which is especially important in view of the recently proposed hypothesis that common multifactorial diseases may be related to rare allelic variants [38]. The mentioned hypothesis fits our study, where a rare allele (C allele) was found to be associated with CKD occurrence.

In conclusion, due to the lack of accordance of previously performed studies it is still impossible to state an unequivocal conclusion regarding the risk associated with the rs 1800471 polymorphism of the TGFB1 gene for elevation of occurrence and progression of CKD as well as hypertension occurrence. That is why it is necessary to perform further studies aimed at identification of genetic risk factors associated with CKD and hypertension in the group of CKD patients. The present study is a preliminary report and the number of patients included in the study will be increased in the future.

\section{References}

1. Coresh J, Selvin E, Stevens LA, et al. Prevalence of chronic kidney disease in the united states. JAMA 2007; 298: 2038-47.

2. Scott GS, John RS, Sudha KI, Barry IF. Familial clustering of chronic kidney disease. Seminars in Dialysis 2007; 20: 229-36.

3. Cargill M, Altshuler D, Ireland J, et al. Characterization of single-nucleotide polymorphisms in coding regions of human genes. Nat Genet 1999; 22: 231-8.

4. Border WA, Noble NA. Transforming growth factor beta in tissue fibrosis. N Engl J Med 1994; 331: 1286-92.

5. Liu Y. Epithelial to mesenchymal transition in renal fibrogenesis: pathologic significance, molecular mechanism, and therapeutic intervention. J Am Soc Nephrol 2004; 15: 1-12.

6. Remuzzi G, Ruggenenti P, Perico N. Chronic renal diseases: renoprotective benefits of renin-angiotensin system inhibition. Ann Intern Med 2002; 136: 604-15.

7. Nakamura T, Miller D, Ruoslahti E, Border WA. Production of extracellular matrix by glomerular epithelial cells is regulated by transforming growth factor-beta 1 . Kidney Int 1992; 41: 1213-21.

8. Li B, Khanna A, Sharma V, et al. TGF-b1 DNA polymorphisms, protein levels, and blood pressure. Hypertension 1999; 33: 271-5.

9. Cambien F, Ricard S, Troesch A, et al. Polymorphisms of the transforming growth factor-betal gene in relation to myocardial infarction and blood pressure: the Etude Castemoin de linfarctus du Myocarde (ECTIM) study. Hypertension 1996; 28: 881-7.

10. Grainger DJ, Heathcote K, Chiano M, et al. Genetic control of the circulating concentration of transforming growth factor type beta1. Hum Mol Genet 1999; 8: 93-7. 
11. Hu BC, Chu SL, Wang GL, et al. Association between genetic variation in transforming growth factors betal and beta3 and renal dysfunction in non-diabetic Chinese. Clin Exp Hypertens 2008; 30: 121-31.

12. Khalil MS, El Nahas AM, Blakemore Al. Transforming growth factor-beta1 SNPS: genetic and phenotypic correlations in progressive kidney insufficiency. Nephron Exp Nephrol 2005; 101: e31-41.

13. Patel A, Scott WR, Lympany PA, et al. The TGF-beta 1 gene codon 10 polymorphism contributes to the genetic predisposition to nephropathy in type 1 diabetes. Diabet Med 2005; 22: 69-73.

14. Ng DP, Warram JH, Krolewski AS. TGF-beta 1 as a genetic susceptibility locus for advanced diabetic nephropathy in type 1 diabetes mellitus: an investigation of multiple known DNA sequence variants. Am J Kidney Dis 2003; 41: 22-8.

15. McKnight A, Savage D, Patterson C, Sadlier D, Maxwell AP. Resequencing of genes for transforming growth factor beta1 (TGFB1) type 1 and 2 receptors (TGFBR1, TGFBR2), and association analysis of variants with diabetic nephropathy. BMC Medical Genetics 2007; 8: 5.

16. Buraczynska M, Baranowicz-Gaszczyk I, Borowicz E, Ksiazek A. TGF-beta1 and TSC-22 gene polymorphisms and susceptibility to microvascular complications in type 2 diabetes. Nephron Physiol 2007; 106: 69-75.

17. Babel N, Gabdrakhmanova L, Hammer MH, et al. Predictive value of cytokine gene polymorphisms for the development of end-stage renal disease. J Nephrol 2006; 19: 802-7.

18. Summers AM, Coupes BM, Brennan MF, et al. VEGF-460 genotype plays an important role in progression to chronic kidney disease stage 5. Nephrol Dial Transplant 2005; 20: 2427-32.

19. Wood NAP, Thomson SC, Smith RM, Bidwell JL. Identification of human TGF-[beta]1 signal (leader) sequence polymorphisms by PCR-RFLP. J Immunol Methods 2000; 234: 117-22.

20. Poggio ED, Wang X, Greene T, Van Lente F, Hall PM. Performance of the modification of diet in renal disease and Cockcroft-Gault equations in the estimation of GFR in health and in chronic kidney disease. J Am Soc Nephrol 2005; 16: 459-66.

21. Schwartz GJ, Haycock GB, Edelmann CM Jr, Spitzer A. A simple estimate of glomerular filtration rate in children derived from body length and plasma creatinine. Pediatrics 1976; 58: 259-63.

22. Levey AS, Eckardt KU, Tsukamoto Y, et al. Definition and classification of chronic kidney disease: a position statement from kidney disease. Improving global outcomes (KDIGO) 2005; 67: 2089-100.

23. Mittal RD, Manchanda PK. Is low-frequency distribution of TGF-beta genotype associated with increased risk for end-stage renal disease? DNA Cell Biol 2007; 26: 172-7.

24. Coll E, Cormand B, Campos B, et al. Association of TGFbeta1 polymorphisms with chronic renal disease. J Nephrol 2004; 17: 794-9.

25. Dell'omo G, Penno G, Pucci L, et al. Lack of association between tgf-\{beta\}-1 genotypes and microalbuminuria in essential hypertensive men. Nephrol Dial Transplant 2009; 28: 28.

26. Kim $Y$, Lee $C$. The gene encoding transforming growth factor \{beta\}1 confers risk of ischemic stroke and vascular dementia. Stroke 2006; 37: 2843-5.

27. Awad MR, El-Gamel A, Hasleton P, et al. Genotypic variation in the transforming growth factor-betal gene: association with transforming growth factor-betal production, fibrotic lung disease, and graft fibrosis after lung transplantation. Transplantation 1998; 66: 1014-20. 28. Yokota M, Ichihara S, Lin TL, Nakashima N, Yamada Y. Association of a T29->C polymorphism of the transforming growth factor-\{beta\}1 gene with genetic susceptibility to myocardial infarction in Japanese. Circulation 2000; 101: 2783-7.

29. Matsuda T, Yamamoto T, Muraguchi A, Saatcioglu F. Crosstalk between transforming growth factor-beta and estrogen receptor signaling through smad3. J Biol Chem 2001; 276: 42908-14.

30. Jafar TH, Schmid CH, Stark PC, et al. The rate of progression of renal disease may not be slower in women compared with men: a patient-level meta-analysis. Nephrol Dial Transplant 2003; 18: 2047-53.

31. Cattran DC, Reich HN, Beanlands HJ, et al. The impact of sex in primary glomerulonephritis. Nephrol Dial Transplant 2008; 23: 2247-53.

32. Iliescu R, Reckelhoff Jf. Sex and the kidney. Hypertension 2008; 51: 1000-1.

33. Locatelli F, Del Vecchio L, Andrulli S, Marai P, Tentori F. The role of underlying nephropathy in the progression of renal disease. Kidney Int Suppl 2000; 75: S49-55.

34. El-Gamel A, Awad MR, Hasleton PS, et al. Transforming growth factor-beta (TGF-beta1) genotype and lung allograft fibrosis. J Heart Lung Transplant 1999; 18: 517-23.

35. Carrieri G, Marzi E, Olivieri F, et al. The G/C915 polymorphism of transforming growth factor beta1 is associated with human longevity: a study in Italian centenarians. Aging Cell 2004; 3: 443-8.

36. Sprangers B, Evenepoel P, Vanrenterghem Y. Late referral of patients with chronic kidney disease: no time to waste. Mayo Clinic Proceedings 2006; 81: 1487-94.

37. Couser W, Riella M. World Kidney Day 2011 - protect your kidneys, save your heart. Arch Med Sci 2011; 7: 1-4.

38. Wilkening S, Chen B, Bermejo IL, Canzian F. Is there still a need for candidate gene approaches in the era of genome-wide association studies? Genomics 2009; 93 : 415-9. 